\title{
A new brontothere from the Eocene of South China
}

\author{
Alexander Averianov, Igor Danilov, Wen Chen, and Jianhua Jin \\ Acta Palaeontologica Polonica 63 (1), 2018: 189-196 doi:https://doi.org/10.4202/app.00431.2017
}

The upper Eocene Youganwo Formation in Maoming Province, Guangdong Province, China, produced abundant remains of turtles and crocodiles, but mammalian remains are rare. The previously found mammals from Youganwo Formation include a nimravid carnivore and an amynodontid perissodactyl. Here we report on a new brontotheriid perissodactyl from the Youganwo Formation. Maobrontops paganus gen. et sp. nov. is described based on a maxillary fragment with $\mathrm{P} 4$ and M1-2 (SYSU-M-4). Maobrontops paganus gen. et sp. nov. is characterized by the combination of a simple $\mathrm{P} 4$ without a hypocone with derived molars having large molar fossae and large anterolingual cingular cusp. A parsimony implied weighting character analysis places Maobrontops gen. nov. in the clade Embolotheriita as a sister taxon to the terminal subclade containing Nasamplus, Protembolotherium, and Embolotherium. Maobrontops paganus gen. et sp. nov. is one of the largest Asian brontotheres. The brontotheriid fauna of South China is endemic and includes at least three valid taxa: Dianotitan from Brontotheriita and Pygmaetitan and Maobrontops gen. nov. from Embolotheriita.

Key words: Mammalia, Perissodactyla, Brontotheriidae, Eocene, China.

Alexander Averianov [dzharakuduk@mail.ru], State Key Laboratory of Biocontrol and Guangdong Provincial Key Laboratory of Plant Resources, School of Life Sciences, Sun Yat-sen University, Guangzhou 510275, China; Zoological Institute of the Russian Academy of Sciences, Universitetskaya Nab. 1, St Petersburg 199034, Russia; and Institute of Geology and Petroleum Technology, Kazan Federal University, Kremlevskaya Str. 4/5, 420008, Kazan, Russia. Igor Danilov [igordanilov72@gmail.com], State Key Laboratory of Biocontrol and Guangdong Provincial Key Laboratory of Plant Resources, School of Life Sciences, Sun Yat-sen University, Guangzhou 510275, China; and Zoological Institute of the Russian Academy of Sciences, Universitetskaya Nab. 1, St Petersburg 199034, Russia. Wen Chen, Shengli State Farm of Guangdong Province, No.3, Xiupeichang of Shengli State Farm, Nantang Town of Gaozhou, Guangdong 525256, China. Jianhua Jin [1ssjih@ mail.sysu.edu.cn], State Key Laboratory of Biocontrol and Guangdong Provincial Key Laboratory of Plant Resources, School of Life Sciences, Sun Yat-sen University, Guangzhou 510275, China. 
This is an open-access article distributed under the terms of the Creative Commons Attribution License (for details please see creativecommons.org), which permits unrestricted use, distribution, and reproduction in any medium, provided the original author and source are credited.

FarF Full text $(503.0 \mathrm{kB})$ ।

FDF Supplementary file $(99.1 \mathrm{kB})$ 